\title{
ÉTICA EMPRESARIAL COMO BASE DE SUSTENTAÇÃO DO PROGRAMA DE COMPLIANCE: UMA BREVE ANÁLISE SOBRE A ÉTICA, A INTEGRIDADE E O COMPLIANCE.
}

\author{
THE CORPORATE ETHICS AS A BASIS FOR SUPPORTING THE COMPLIANCE \\ PROGRAM: A BRIEF ANALYSIS ON ETHICS, INTEGRITY AND COMPLIANCE.
}

\author{
Enoque Feitosa Sobreira Filho ${ }^{1}$ \\ Flavia Piva Almeida Leite ${ }^{2}$ \\ José Alberto Monteiro Martins ${ }^{3}$
}

\begin{abstract}
${ }^{1}$ Coordenador Nacional do GT "Ética e Cidadania" da Associação Nacional de Pós-Graduação em Filosofia, com mandato até 2020. Fez Graduação em Direito na UFPE. Mestrado em Direito pela mesma instituição. É Doutor em Direito pela UFPE e Doutor em Filosofia pela UFPB. Possui estágio Pós-doutoral em Filosofia do direito pela UFSC. Professor Associado na UFPB, lecionando na Graduação e Pós-Graduação em Direito e em Filosofia. Advogado (licenciado). Professor-visitante da Universidade Eduardo Mondlane (Moçambique). Consultor ad hoc da CAPES. É membro de grupos de pesquisa em diversas I.E.S. do país e no exterior. Líder, no âmbito da UFPB, dos Grupos de Pesquisa "Marxismo e Direito" e "Direito, linguagem jurídica e poder" e "Filosofia do direito", que envolve alunos da graduação e da pós-graduação em Direito e em Filosofia. É membro efetivo de várias associações científicas nacionais e internacionais, dentre elas, a Strikes and Social Conflicts International Association - SSCIA; da Associação Nacional de Pós-Graduação em Filosofia - ANPOF; da Associação Brasileira de Filosofia do Direito - ABRAFI, do IVR - Internationale Vereinigung für Rechts und Sozialphilosophie (IVR). É sócio-fundador da Sociedade Ibero-Americana de Retórica. Foi Coordenador do Programa de Pós-Graduação em Ciências Jurídicas da UFPB (Mestrado e Doutorado) durante o quinquênio 2009-2013 e responsável pela área de concentração do Doutorado em 2014-2015. Membro do Conselho Editorial da Revista "Crítica Marxista". Foi proponente, junto a CAPES e, nessa condição, é coordenador do DINTER em Direito entre a UFPB e a UFPI. Coordena o Projeto Internacional CAPES /AULP "O direito entre garantias formais e as demandas por sua concretização" envolvendo a UFPB e a Universidade Nacional Eduardo Mondlane (Moçambique). Tem publicações completas em eventos científicos no exterior, com financiamento AEX/CAPES e fez da parte da equipe responsável pela biblioteca de referência da área de direito da CAPES, sob responsabilidade da UFPB.

${ }^{2}$ Professora da Faculdade de Arquitetura, Artes e Comunicação - no Departamento de Ciências Humanas da FAAC/UNESP. Professora do Programa de Mestrado em Direito da UNESP/Franca. Líder do grupo de pesquisa "Direito à inclusão e acessibilidade das pessoas com deficiência e mobilidade reduzida, credenciado junto ao CNpq. Tem experiência nos seguintes temas: relacionados à Administração Pública municipal e ao Direito Público, pessoa com deficiência, inclusão social, eliminação das barreiras arquitetônicas, desenho universal, acessibilidade, convenção dos direitos das pessoas com deficiência e direito urbanístico, sociedade da informação. Doutora em Direito do Estado pela PUC/SP na sub-área Direito Urbanístico, Mestrado pela Instituição Toledo de Ensino Bauru em Sistema Constitucional de Garantia de Direitos, pós graduada em Gerente de Cidades pela Fundação Armando Alvares Penteado - FAAP e Bacharel em Direito pela Instituição Toledo de Ensino de Bauru - ITE. Atuou como advogada no Serviço de Água e Esgoto do Município de Jahu SAEMJA, principalmente na gestão pública e no contencioso trabalhista e civil. Foi Coordenadora e Professora da Pós Graduação no Centro Universitário Octávio Bastos.

${ }^{3}$ Doutorando em Direito Empresarial e Cidadania pelo Centro Universitário Curitiba. Mestre em Direito Empresarial e Cidadania pelo Centro Universitário Curitiba (2014). Especialista em Direito Empresarial pela Fundação Getúlio Vargas (2002). Bacharel em Direito com especialização em direito empresarial pela Universidade de São Paulo (1983). Advogado e consultor. E-mail: alberto.moma@gmail.com.
\end{abstract}




\section{RESUMO}

O foco deste estudo é analisar os conceitos de ética empresarial, integridade e compliance com o objetivo de entender o significado desses institutos, a relação e as distinções entre eles, levando-se em consideração a legislação, os princípios e a experiência estadunidense e brasileira sobre o tema. Para tanto, complementa-se o estudo com um breve histórico da origem desses institutos. A metodologia de pesquisa adotada consiste nas investigações e observações históricas dos eventos mais relevantes. O trabalho orienta-se por uma análise crítica do Compliance Manual do Departamento de Justiça dos Estados Unidos da América, e da Lei no. 13.467/2017, e seus reflexos no ambiente econômico, social e empresarial. A pesquisa é qualitativa, de caráter exploratório, desenvolvida por meio de análise bibliográfica e documental. As fontes bibliográficas e documentais empregadas consistem na pesquisa de livros, revistas científicas, periódicos e artigos retirados da internet, bem como de legislação. A investigação é realizada por meio do método hipotético-dedutivo de abordagem, por intermédio de uma análise dogmática dos conceitos de ética empresarial, integridade e compliance. Como resultado da pesquisa, concluiu-se que, na essência, ética e compliance são lados diferentes da mesma moeda. Nesse prisma, compliance atém-se ao cumprimento da lei, enquanto a ética requer que seja feito o que é correto, independentemente do que reza a lei. $\mathrm{O}$ contexto ético é a base para o programa de compliance, considerando-se que a ética e a integridade dão sustentação e sentido ao programa de compliance. $\mathrm{O}$ sistema de compliance somente dará resultado se houver uma forte cultura ética. $O$ estudo oferece como contribuição a análise sobre as duas teorias que dão base ao compliance, as teorias racionalista e normativa, bem como o esclarecimento sobre conceitos e definições que confundem muitos profissionais da área de compliance.

PALAVRAS-CHAVE: ética empresarial; compliance; integridade; código de conduta; moral.

\section{ABSTRACT}

The focus of this study is to analyze the concepts of business ethics, integrity and compliance in order to understand the meaning of these institutes, the relationship and the distinctions between them, taking into consideration US and Brazilian legislation, principles and experience on this theme. The study is complemented by a brief history of the origin of these institutes. The research methodology adopted consists of investigations and historical observations of the most relevant events. The study is guided by a critical analysis of the US Department of Justice's Compliance Manual and Law no. 13,467/2017, and its effects on the economic, social and business environment. The research is qualitative, exploratory, developed through bibliographic and documentary analysis. The bibliographic and documentary sources employed consist of searching books, scientific journals, journals and articles taken from the Internet, as well as legislation. The investigation is conducted through the hypothetical-deductive method of approach, through a dogmatic analysis of the concepts of business ethics, integrity and compliance. As a result of the research, it was concluded that, in essence, ethics and compliance are different sides of the same coin. In this sense, compliance aims the accomplishment of the law, while ethics requires doing what is right, regardless of what the law says. The ethical context is the basis for the compliance program, 
considering that ethics and integrity support the compliance program. The compliance system will only work if there is a strong ethical culture. The study provides a contribution of an analysis of the two theories that underlie compliance, the rationalist and normative theories, as well as concepts and definitions that confuse many professionals of compliance area.

KEYWORDS: corporate ethics; compliance; integrity; code of ethics; moral.

\section{INTRODUÇÃO}

O aumento da atenção aos programas de compliance e ao tema de ética empresarial e integridade no mundo corporativo refletem a importância prática crescente do assunto. As consultorias no campo da ética empresarial também aumentaram significativamente em razão dos vários escândalos corporativos e o desejo das empresas de evitá-los no futuro.

Apesar desse crescimento da ética nos negócios e a aparente aceitação de sua importância, há muitas questões que ainda devem ser debatidas; por exemplo, quais fatores influenciam atualmente o comportamento ético? Em que devem consistir as obrigações éticas de uma empresa? Como a ética empresarial pode ser integrada da melhor maneira na cultura corporativa? O que pode ser feito em atividades de ética empresarial para a empresa precaverse contra o risco dos desvios de conduta de seus colaboradores? O esforço educativo silencia a voz dos interesses e controla as ambições desmedidas, eliminado as tentações? As práticas de ética organizacional poderiam coibir o capricho de seus colaboradores, incutir-lhes o senso de lealdade? Quais intervenções seriam necessárias? Ainda não há resposta para muitas perguntas. Os conceitos e definições que regem a ética empresarial e o compliance ainda estão em processo de uniformização.

No segundo capítulo deste estudo abordar-se-á a conjuntura histórica a partir do século XIX, que proporcionou a evolução do comportamento ético nas empresas e o acelerou a partir dos escândalos da década de 1970 nos Estados Unidos da América, bem como seu desenvolvimento tardio na América Latina.

No terceiro capítulo tratar-se-á do conceito de ética empresarial, seu conjunto de valores, princípios e fins que orientam o comportamento da organização e compõem a sua cultura corporativa, influenciando as suas estratégias, estrutura, decisões e as suas mais diversas operações.

No quarto capítulo serão abordados o conceito de compliance e o conteúdo dos programas de compliance, bem como as teorias racionalista e normativa que atribuem visões 
diferentes no comportamento e nas motivações não explícitas dos agentes relativamente ao cumprimento de compliance.

Em sequência, no capítulo quinto analisa-se o tema de integridade; não só na definição de conceitos e hierarquias, como também da boa escolha do legislador brasileiro em utilizar esta expressão como um programa de integridade, regulamentado pela Lei $\mathrm{n}^{\circ}$. 12.846/2013.

No último capítulo, a partir da intelecção dos conceitos acima expostos de ética empresarial, compliance e integridade, estudar-se-á a estudar a dinâmica entre eles, cujos conceitos sobrepõem-se em vários aspectos e são objeto de interpretações diversas, mesmo no entendimento de profissionais da área de compliance.

A metodologia utilizada nesta pesquisa é qualitativa, de caráter exploratório, desenvolvida por meio de análise bibliográfica e documental. As fontes bibliográficas e documentais empregadas consistem na pesquisa de livros, revistas científicas, periódicos e artigos retirados da internet, bem como de legislação. A investigação é realizada por meio do método hipotético-dedutivo de abordagem, por intermédio de uma análise dogmática dos conceitos de ética empresarial, integridade e compliance.

\section{A ÉTICA EMPRESARIAL}

\subsection{UM BREVE HISTÓRICO: ESTADOS UNIDOS DA AMÉRICA}

Como ponto de partida neste estudo, o presente capítulo limita-se a apresentar um breve histórico da ética empresarial partir do século XIX, na perspectiva dos Estados Unidos da América (incluindo a Escola de Chicago), constatando-se que essa evolução ocorreu concomitantemente ao amadurecimento pós-revolução industrial, e também como resposta aos escândalos de corrupção nas décadas a partir de 1960.

Há pouco tempo, houve uma mudança na percepção dos administradores e sócios das empresas. No passado não remoto, o princípio que orientou a conduta das empresas era a maximização do lucro. A função da empresa consistia majoritariamente na busca do bemestar dos sócios e a perseguição irrestrita do lucro. Cabe ressaltar que a utilização da ética na condução das organizações não é nova; o que se valoriza atualmente é a faculdade de os gestores poderem administrar códigos morais como administram os demais programas e processos da organização. 
Ao referir-se ao passado, Wayne Norman ${ }^{4}$ (Harvard Business School) analisa que o tema da ética empresarial vem sendo estudado por filósofos há centenas de anos, com avaliações práticas, virtudes e vícios no comércio e no empréstimo de dinheiro. A influência potencial da corrupção também era uma preocupação desses pensadores clássicos tanto quanto se atém hoje a este tema, com a influência potencialmente corrupta da riqueza na vida comunitária e política. A propriedade da terra era o principal veículo a trazer riqueza e poder comercial até a revolução industrial no final do século XVIII.

Neste caminho, o amadurecimento das economias a partir do século XVIII até o início do século XX levou ao questionamento de temas importantes da economia política, relativos aos direitos dos trabalhadores e a ética do lobby, para as justificativas e críticas do capitalismo e modelos socialistas de propriedade, discutidos por Adam Smith, John Stuart Mill e Karl Marx entre outros. Essas questões permanecem relevantes para o que atualmente denominase ética nos negócios no sentido mais amplo, mesmo que a maioria dos estudiosos de negócios entenda que a ética pressupõe como ponto de partida a legitimidade básica dos mercados privados de bens, serviços, trabalho e capital, juntamente com a legitimidade da regulamentação governamental de tais mercados. ${ }^{5}$

Gabriel Abend $^{6}$ (Universidade de Nova Iorque) esclarece que o tema da ética empresarial começou a ser tratada nas escolas de administração estadunidenses no início do século XX, no entanto, ainda não se identificava naquela época uma comunidade acadêmica de especialistas em ética até as décadas de 1970 ou 1980. Neste contexto, cabe relatar que a grande Enciclopédia de Filosofia, editada por Paul Edwards, considerada a obra de referência em filosofia por duas décadas após sua publicação em 1967, não apresentou referência alguma a ética nos negócios.

Ressalta-se que, em 1972, ocorreu a expansão das multinacionais ${ }^{7}$ oriundas principalmente dos Estados Unidos e da Europa, com a abertura de subsidiárias em todos os continentes. Nos novos Estados em que as multinacionais passaram a operar, por vezes choques culturais e outras formas de fazer negócios conflitavam com os padrões de ética das

\footnotetext{
4 NORMAN, Wayne. Business Ethics. Harvard Business School. Disponível em: <https:/www.hbs.edu/faculty/conferences/2016-newe/Documents/Norman,\%20Business \%20Ethics,\%20IntEncycEthics.pdf>. Acesso em: 30 dez. 2019.

${ }^{5}$ NORMAN, 2016.

6 ABEND, Gabriel. 2011. Historicizing Business Ethics: The Origins of Business Ethics in American Universities, 1902-1936. Department of Sociology, New York University, unpublished manuscript. Disponível em: <https://www.researchgate.net/publication/268279608_ _The_Origins of_Busines s _Ethics_in_American_Universities_1902-1936>. Acesso em: $30 \mathrm{dez} .2019$.

${ }^{7}$ Atualmente denominadas empresas transnacionais.
} 
matrizes dessas companhias, fato que incentivou a realização de códigos de ética corporativos.

Posteriormente, em 1977, o governo estadunidense legislou sobre a ética empresarial, através da edição da lei denominada Foreign Corrupt Practices Act, que proíbe e estabelece penalidades às pessoas ou organizações estadunidenses que ofereçam subornos às autoridades estrangeiras fora dos Estados Unidos da América, com a finalidade de obter negócios ou contratos.

Nas últimas décadas do século XX, nos Estados Unidos da America, devido aos grandes escândalos corporativos, aumentou significativamente a quantidade de faculdades de administração e negócios para atender à demanda de ensino de ética aos futuros líderes corporativos. Por conseguinte, após 1970 também aumentou a produção de livros didáticos sobre ética empresarial, cujos nomes mais famosos são Tom Beauchamp e Norman Bowie (Ethical Theory and Business, 1979; e Ethical Issues in Business: A Philosophical Approach, 1979), Richard T. de George (Business Ethics, 1982), John Boatright e Patricia Werhane e Manuel G. Velasquez (Ethics: Concepts and Cases, 1982).

Paralelamente ao maior foco no questionamento da ética empresarial, foram constituídas instituições dedicadas ao estudo da ética empresarial, tais como a Society for Business Ethics e Association for Practical and Professional Ethics, ambas localizadas nos Estados Unidos da América, e a associação europeia European Business Ethics Network, constituídas entre 1980 e 1987, dando também origem a revistas especializadas, como o Journal of Business Ethics, cuja publicação iniciou-se em 1982, a Business Ethics Quarterly, em 1991 e a Business Ethics: a European Review, em 1992. As reuniões anuais das associações permitiram avançar no estudo da ética empresarial, tanto conceitualmente quanto em sua aplicação às empresas; surgindo nessa época a publicação de duas enciclopédias, uma nos Estados Unidos da América e outra na Alemanha, denominadas Encyclopedic Dictionary of Business Ethics e Lexikon der Wirtschaftsethik.

A entrada do verbete Ética Empresarial na recente Encyclopedia of Business Ethics and Society, de autoria de Robert W. Kolb (Professor de Finanças da Escola de Negócios da Universidade Loyola de Chicago) incluiu um capítulo denominado A Brief History of Business Ethics ${ }^{8}$ e menciona as discussões sobre ética nos negócios no Velho Testamento, Talmud, Novo Testamento e Alcorão e o tema dos monopólios e escravidão no século XIX. Adicionalmente, o estudo resume o tratamento da ética empresarial nos tempos recentes, com

\footnotetext{
${ }^{8}$ KOLB, Robert W. Encyclopedia of business ethics and society. ISBN 978-1-4129-1652-3. Thousand Oaks, Califórnia: SAGE Publications, Inc., 2008, p. 217.
} 
foco nos Estados Unidos da América, mostrando claramente que os escândalos corporativos ocorridos naquele Estado foram o vetor para discussão do tema, o aprofundamento de seu significado e também o motivo para a publicação de normativos legais e uma expectativa de mudança de atitude por parte das empresas estadunidenses:

\begin{abstract}
Nos últimos tempos, a ética nos negócios passou por vários estágios de desenvolvimento. Antes da década de 1960, os negócios eram normalmente considerados uma atividade amoral; conceitos como ética e responsabilidade social raramente eram mencionados explicitamente. Durante a década de 1960, começaram a surgir várias questões sociais nos negócios, incluindo direitos civis, meio ambiente, segurança no local de trabalho e questões do consumidor. No final da década de 1970, o campo da ética nos negócios começou a se estabelecer na academia, com várias escolas americanas começando a oferecer um curso em ética nos negócios em 1980. De 1980 a 1985, o campo da ética nos negócios continuou a se consolidar, com o surgimento de periódicos, livros didáticos, centros de pesquisa e conferências. De 1985 a 1995, a ética nos negócios integrou-se às grandes corporações, com o desenvolvimento de códigos de ética corporativa, treinamento em ética, linhas diretas de ética e diretores de ética. De 1995 a 2000, questões relacionadas à atividade internacional de negócios vieram à tona, incluindo questões de suborno e corrupção de funcionários do governo, uso de trabalho infantil por fornecedores estrangeiros e a questão de operar em países onde as violações dos direitos humanos estavam ocorrendo. A partir de 2000 até hoje, a discussão sobre ética nos negócios concentrou-se principalmente em grandes escândalos corporativos, como Enron, WorldCom e Tyco, levando a uma nova fase de regulamentação do governo (por exemplo, a Lei Sarbanes-Oxley de 2002) e aplicação. ${ }^{9}$
\end{abstract}

\title{
2.2 UM BREVE HISTÓRICO: AMÉRICA LATINA
}

Na sequência, cabe aqui uma breve explanação sobre a evolução do conceito de ética nos negócios e nas empresas na América Latina, que teve início por meio de esforços isolados de pesquisadores e professores universitários, ao lado de subsidiárias de empresas transnacionais na América Latina. Como resultado do I Congresso Latino Americano de Ética, Negócios e Economia, em julho de 1998, sediado no Brasil, foi constituída a

\footnotetext{
${ }^{9}$ Texto original em inglês:" In recent times, business ethics has moved through several stages of development. Prior to the 1960s, business was typically considered to be an amoral activity; concepts such as ethics and social responsibility were rarely explicitly mentioned. During the 1960s, a number of social issues in business began to emerge, including civil rights, the environment, safety in the workplace, and consumer issues. During the late 1970s, the field of business ethics began to take hold in academia, with several U.S. schools beginning to offer a course in business ethics by 1980. From 1980 to 1985, the business ethics field continued to consolidate, with the emergence of journals, textbooks, research centers, and conferences. From 1985 to 1995, business ethics became integrated into large corporations, with the development of corporate codes of ethics, ethics training, ethics hotlines, and ethics officers. From 1995 to 2000, issues related to international business activity came to the forefront, including issues of bribery and corruption of government officials, the use of child labor by overseas suppliers, and the question of whether to operate in countries where human rights violations were taking place. From approximately 2000 until today, business ethics discussion has mainly been focused on major corporate scandals such as Enron, WorldCom, and Tyco, leading to a new phase of government regulation (e.g. the Sarbanes-Oxley Act of 2002) and enforcement."
} 
Associação Latino-americana de Ética, Negócios e Economia - ALENE, para dar-se continuidade aos contatos para aprofundamento de pesquisas e sedimentação dos conhecimentos específicos da região em matéria de ética empresarial.

No Brasil, o estudo acadêmico da ética empresarial iniciou-se em São Paulo, na Escola Superior de Administração de Negócios (ESAN), que foi a primeira faculdade de administração do Brasil, fundada em 1941, a privilegiar o ensino da ética nos cursos de graduação desde seu início.

Em 1992, o Ministério da Educação e Cultura recomendou a inclusão da disciplina de ética nos cursos de administração, o que foi seguido por muitas faculdades de administração de empresas em todo o Brasil. Em 1992, também foi constituído o Centro de Estudos de Ética nos Negócios (CENE), que foi ampliado em $1997^{10}$ por solicitação dos estudantes da Escola de Administração de Empresas de São Paulo da Fundação Getulio Vargas (FGV) após vários projetos de pesquisa desenvolvidos com empresas. O CENE-EAESP-FGV foi um polo de irradiação da ética empresarial por suas intensas realizações no Brasil e no exterior, através de ensino, pesquisas, publicações e eventos.

No Brasil, o assunto relativo à ética empresarial tomou força com a constituição do Instituto Brasileiro de Governança Corporativa (IBGC) em 1995. O objetivo do IBGC é tornar-se referência nacional no mundo da governança corporativa, contribuindo para gerar e disseminar conhecimento sobre as melhores práticas de governança corporativa e influenciar os mais diversos agentes em sua adoção, contribuindo para o desempenho sustentável das organizações e, consequentemente, para uma sociedade melhor. A principal publicação do IBGC é o Código das Melhores Práticas de Governança Corporativa, lançado em 1999 e atualmente em sua quinta edição. ${ }^{11}$

Não menos importante, apesar de bem recente, ocorreu a constituição do Instituto Brasileiro de Direito e Ética Empresarial (IBDEE), em 2017, cujo objetivo é ser referência no estudo de Direito com foco na promoção da ética empresarial, almejando uma atuação com rigor científico, criatividade e respeito à ordem constitucional, objetivando influenciar os agentes sociais para um comportamento mais responsável, transparente e ético nos negócios. ${ }^{12}$

É importante ressaltar, em síntese, que o Brasil, apesar de ter no passado promulgado legislação específica sobre várias matérias que abordam a ética empresarial, tal como o abuso

\footnotetext{
${ }^{10}$ A partir de 1997 o CENE passou a ser denominado Centro de Estudos de Ética nas Organizações com a introdução de novas atividades.

${ }^{11}$ INSTITUTO BRASILEIRO DE GOVERNANÇA CORPORATIVA. Disponível em: < https://ibgc.org.br/>. Acesso em 2 jan. 2020.

12 INSTITUTO BRASILEIRO DE DIREITO E ÉTICA EMPRESARIAL. Disponível em:< http://www.ibdee.org.br/>. Acesso em: 2 jan. 2020.
} 
do poder econômico e práticas anticoncorrenciais em 1962, bem como em outras áreas, como recursos humanos, meio-ambiente e consumidor, não abordou o tema em sua integralidade como o fez os Estados Unidos da América e a Europa há mais tempo.

No próximo capítulo serão estudados os conceitos de ética e ética empresarial, seu conjunto de valores e princípios, bem como as melhores práticas.

\section{O CONCEITO DE ÉTICA EMPRESARIAL}

Passa-se, adiante, ao conceito de ética empresarial, também denominada de ética organizacional. Muito se lê e se discute na pós-modernidade sobre a (falta de) ética empresarial. O que vem a ser a ética empresarial, afinal, considerando-se uma definição globalizada?

Antes de iniciar-se o estudo da ética empresarial, para um bom entendimento de conceitos, entende-se importante definir, de forma breve e simples, o significado de ética, de forma geral, no entendimento de Robert Henry Srour:

A ética é um saber científico que se enquadra no campo das Ciências Sociais. É uma disciplina teórica, um sistema conceitual, um corpo de conhecimentos que torna inteligíveis os fatos morais. Mas o que são fatos morais? São fatos que implicam escolhas que os agentes fazem entre o bem e o mal [...] com base em juízos de valor [...] apreciações sobre o que considera aceitável ou inaceitável à luz dos valores que prezam. ${ }^{13}$

Em outra perspectiva, Adolfo Sanchez Vasques analisa as doutrinas éticas em geral e seu dinamismo no espaço e no tempo em função do comportamento moral:

As doutrinas éticas fundamentais nascem e se desenvolvem em diferentes épocas e sociedades como respostas aos problemas básicos apresentados pelas relações entre os homens e em particular pelo seu comportamento moral efetivo. Por isto, existe uma estreita vinculação entre os conceitos morais e a realidade humana, social, sujeita historicamente à mudança. Por conseguinte, as doutrinas éticas não podem ser consideradas isoladamente, mas dentro de um processo de mudança e de sucessão que constitui propriamente a sua história. ${ }^{14}$

\footnotetext{
${ }^{13}$ SROUR, Robert H. Ética Empresarial. Rio de Janeiro: Elsevier, 2013, p. 4.

${ }^{14}$ VÁSQUEZ, Adolfo Sanches. Ética. 14.ed. Rio de Janeiro: Civilização Brasileira, 1993, p. 235.
} 
Ao tratar da implantação do conhecimento ético de forma participativa, Robert Henry Srour assevera que essa atitude transforma a investigação ética em bussola moral para o dia a dia:

\begin{abstract}
O conhecimento ético traz à tona questões polêmicas e desenha um leque de opções para enfrentá-las. Ao ser convertido em pano de fundo das estratégias empresariais, evita o confronto da permissividade ou a preguiça da omissão,contribui par manter a coesão organizacional e cria um escudo contra as crises. [...] O conhecimento ético tem a virtude de oferecer um quadro de referência para as ações corporativas, porque exige análise de conjunto, mapeia o peso desigual dos públicos de interesse (partes interessadas na organização ou stakeholders) e traça cenários consistentes para a tomada de decisão. ${ }^{15}$
\end{abstract}

Aduz, ainda, o autor, ao tratar da inobservância de atitudes éticas, que a competição resvala muitas vezes para a concorrência desleal e, também, há a pressão dos clientes. O remédio para as atitudes que estão em desacordo com a ética empresarial é a instituição de um pensamento eticamente orientado, que reduz a vulnerabilidade das empresas; "assume o papel de diferencial competitivo e serve de nervura para a perpetuidade do negócio."16

A ética deixou de ser uma questão estritamente do indivíduo que enfrenta dilemas morais em sua vida, adquirindo uma dimensão maior, denominada a organizacional ou empresarial, que impacta o público interno, especificamente os empregados, e a sociedade como um todo, passando a ser objeto de estudo do comportamento organizacional. ${ }^{17}$

Do ponto de vista acadêmico, a ética empresarial atualmente é tratada como uma ciência ética específica. Richard de George foi o precursor em distinguir a ética empresarial como uma disciplina separada de estudo, considerando-a independente, na medida em que lida com um conjunto de questões inter-relacionadas a serem desvendadas e endereçadas dentro de uma estrutura abrangente. Mark S. Schwartz entende que o marco teórico não é dado por teoria ética alguma, mas pela interdependência sistemática das questões éticas empresariais, que pode ser abordada a partir de vários aspectos filosóficos, teológicos ou outros pontos de vista. ${ }^{18}$

Wayne Norman analisa a característica interdisciplinar da ética empresarial:

\footnotetext{
${ }^{15}$ SROUR, Ibid., p. 4.

${ }^{16}$ SROUR., 2013, p. 3

${ }^{17}$ CARDOSO, C.C. Éticas e política éticas em contexto empresarial. (Org.) RODRIGUES, S. B.; CUNHA, M. P. Estudos organizacionais: novas perspectivas na administração de empresas: uma coletânea luso-brasileira. Iglu: SP, 2000, p. 306-334.

18 SCHWARTZ, Mark S. Business Ethics as an Academic Field in Encyclopedia of business ethics and society. ISBN 978-1-4129-1652-3. Thousand Oaks, Califórnia: SAGE Publications, Inc., 2008, p. 217.
} 
'Ética empresarial' é um rótulo conciso, mas de muitas maneiras enganoso, para um campo interdisciplinar que abrange uma vasta gama de questões normativas no mundo empresarial. $\mathrm{O}$ rótulo presta-se mais diretamente a um conjunto principal de perguntas sobre como os indivíduos no mundo dos negócios deve comportar-se ou a quais princípios eles podem recorrer para negociar dilemas morais no trabalho. Mas se considerarmos a variedade de tópicos cobertos nas principais revistas ou livros de ética nos negócios, vemos que essas questões sobre virtudes individuais e tomada de decisão ética são cercadas por questões envolvendo organizações e instituições. Em outras palavras, a ética nos negócios no sentido mais amplo também pergunta sobre as estruturas mais adequadas ou justas para as empresas, mercados, regulamentos de mercado e supervisão política em uma sociedade democrática e de economia globalizada. ${ }^{1920}$

A ética empresarial é composta por um conjunto de valores, princípios e fins que orientam o comportamento da organização e compõem a sua cultura corporativa, influenciando as suas estratégias, estrutura, decisões e as suas mais diversas operações. ${ }^{21}$ Pode-se afirmar com segurança que não há organização sustentável sem ética empresarial. De uma maneira ou de outra, em algum momento, a conduta ou a má reputação de uma empresa acabará por afetar suas relações com os clientes, a permanência dos colaboradores, enfim, o seu crescimento e a sua continuidade no mercado.

Os valores e princípios éticos guiam a governança da organização para que a entidade jurídica não seja conduzida apenas de acordo com a vontade dos tomadores de decisão; impõem limites à discricionariedade dos administradores e à própria ação da organização, que passa a ter uma identidade e um modelo próprios de governança, independentemente de quem sejam os administradores que fazem a gestão da empresa. As organizações devem ser entidades éticas que se orientam segundo valores, padrões e melhores práticas que lhes dão certa identidade e unidade de sentido. ${ }^{22}$

Contemporaneamente, a forma como as empresas são administradas é considerado um tema de interesse coletivo, ou seja, de seus stakeholders ${ }^{23}$. As decisões tomadas pelas

\footnotetext{
${ }^{19}$ NORMAN, 2016.

20 Texto original em inglês: "Business ethics" is a concise, but in many ways misleading, label for an interdisciplinary field covering a vast range of normative issues in the world of commerce. The label lends itself most directly to a core set of questions about how individuals in the business world ought to behave, or what principles they might appeal to in order to negotiate moral dilemmas at work. But if we consider the array of topics covered in the leading business ethics journals or textbooks, we see that these core issues about individual virtues and ethical decision-making are surrounded by layers of issues involving organizations and institutions. In other words, business ethics in the broadest sense also inquires about the most appropriate or just designs for firms, markets, market regulations, and political oversight in a democratic society and a globalized economy."

${ }^{21}$ LAMBOY, Christian K. de.; Risegato, Giulia G.A. Pappalardo; COIMBRA, Marcelo de Aguiar.Introdução ao Corporate Compliance, Ética e Integridade. Manual de Compliance. São Paulo: Instituto ARC, 2017, p. 19 e ss, ${ }^{22}$ LAMBOY, Ibid.

${ }^{23}$ Stakeholder é um termo da língua inglesa que tem como significado "grupo de interesse". Fazem parte deste grupo as pessoas que possuem algum tipo de interesse nos processos e resultados da empresa. Esses interesses podem ser, além dos processos e resultados, no planejamento dos projetos ou negócios, de modo positivo ou
} 
empresas afetam a vida das pessoas em geral, não apenas dos colaboradores, terceiros e consumidores que mantêm uma relação direta, mas da comunidade como um todo. As empresas são entidades éticas, que se orientam segundo valores padrões e melhores práticas, que lhes concedem uma identidade corporativa.

Entende-se como uma atribuição importante da empresa, na concepção da ética empresarial, orientar seus gestores e colaboradores, por meio de um conjunto de teorias, técnicas e instrumentos, nas tarefas de conceber, usar limites e normas (princípios, valores e regras) éticas em suas atividades. ${ }^{24}$

Robert Henry Srour definiu ética empresarial como a prática organizacional baseada em valores morais e destacou sete dimensões teóricas: a) a qualidade no trabalho e o respeito no trato interpessoal; b) os valores de igualdade de oportunidades e o tratamento não discriminatório; c) a importância do cliente; d) o respeito pelos prazos; e) a confiabilidade, a credibilidade e a estabilidade de normas e objetivos; f) a capacitação e o autodesenvolvimento; e g) o comprometimento com normas sociais e a integração com a comunidade. $^{25}$

Sob outro prisma, Christian Lamboy entende que as melhores práticas de incorporação ou disseminação cultural de limites e normas éticas são: a concepção de códigos morais; o engajamento e o diálogo com stakeholders; os processos estruturados de tomada de decisão que incluem: a resolução de conflitos de interesses, os dilemas éticos e as questões de justiça; a análise de desvios de conduta e comportamento; o programa e a educação continuada em ética; e gestão de indicadores e pesquisas de clima ético. ${ }^{26}$

Enfatiza-se que a afirmação de regras de conduta ética leva a empresa a uma identidade de fato para sua atividade e perante a sociedade, seus parceiros, clientes, fornecedores e autoridades, surgindo a sua cultura organizacional. Tendo em vista que as empresas também se relacionam com outras instituições, a ética empresarial deve ser compreendida, ainda, em todas essas relações. Assim, a ética empresarial está diretamente ligada aos clientes, fornecedores, parceiros e quaisquer stakeholders com os quais a organização esteja envolvida dentro da sua área de atuação. Esta afirmação significa que a ética empresarial é inerente - uma vez que rege a conduta dos colaboradores e gestores entre si - e exterior, já que também fundamenta as relações com o mercado.

negativo. A quantidade de stakeholders demonstra a visibilidade e a importância que os projetos da empresa possui. Alguns exemplos desses grupos de interesse são: acionistas, investidores, proprietários, empregados, sindicatos, clientes, governo e concorrentes.

${ }^{24}$ LAMBOY, 2017.

${ }^{25}$ SROUR, 2013.

${ }^{26}$ LAMBOY, op. cit. 
O compliance pode ser definido como um estado de acordo entre o comportamento do agente de um lado e as regras explícitas pré-definidas, procedimentos, convenções, padrões, diretrizes, princípios, legislação ou outras normas, do outro lado. É também um veículo para a disseminação e o reforço da ética empresarial

Embora o compliance não seja focado em normas implícitas e de espírito mais amplo, reconhece-se relativamente princípios (de alto nível) como normas - na condição de que são feitas de forma explícita. Um estado de conformidade pode ser alcançado independentemente das motivações, causas ou circunstâncias que levaram ao estado de conformidade. Ralph Foorthuis e Erik Bos entendem, entretanto, que um agente pode estar em conformidade sem internalizar as normas e sem necessariamente mudar suas convicções e opiniões ou comportamento; além do mais, o compliance não intencional também é compliance. Finalmente, os autores consideram que o compliance deveria distinguir-se de efetividade, pois um estado de conformidade não necessita necessariamente resultar no alcance dos objetivos desejados. ${ }^{2728}$

As ponderações dos autores acima citados trazem uma percepção mais profunda do tema. Ao abordar normas implícitas e de espírito mais amplo, em realidade, os autores entram no campo de valores e princípios, ou sejam, da ética e integridade.

Similarmente ao que ocorre em português e no Brasil, nota-se claramente que, em inglês, também é utilizado para o termo conformity o significado de compliance, ou seja, adherence to prescribe rules; da mesma forma, em português, no Brasil, utiliza-se compliance e conformidade indistintamente, com o significado de aderência às regras pré-estabelecidas.

Apesar de compliance e conformidade serem usados como sinônimos, o compliance refere-se a uma recomendação explícita ou implícita e a conformidade refere-se a um estado

\footnotetext{
${ }^{27}$ FOORTHUIS, Ralph; BOS, Erik. A Framework for Organizational Compliance Management Tactics. $2014 . \quad$ Disponível em: <https://www.researchgate.net/publication/220920993_A_Framework_for_Organizational_Compliance_Manage ment_Tactics>. Acesso em: 3 jan. 2020.

${ }^{28}$ ZAELKE, D., KANIARU, D., KRUZIKOVÁ, E. Making Law Work: Environmental Compliance \& Sustainable Development, Vol. I \& II. London: Cameron May Ltd. (2005); e também MITCHELL, R. B. Compliance Theory: An Overview. In: CAMERON, J., WERKSMAN, J.,

RODERICK, P. (eds.). Improving Compliance with International Environmental Law. London: Earthscan, 1996.Disponível em: <https://rmitchel.uoregon.edu/sites/rmitchel1.uoregon.edu/files/resume/chapters/1996ComplianceTheory.pdf>. Acesso em: 3 jan. 2020.
} 
de acordo na falta de uma ordem, de forma que conformity (conformidade) pode necessariamente envolver uma mudança de convicção ou comportamento, enquanto que um agente pode estar em compliance sem uma mudança de convicção. ${ }^{29}$

O compliance permite que cada pessoa conheça melhor a sua função dentro da empresa, os limites de sua atuação e entenda melhor o que deve fazer em determinadas situações. Isso faz com que haja um funcionamento mais eficiente da empresa, dentro de limites de licitude, além de uma solução mais rápida para os problemas que eventualmente aparecerem. Além disso, o compliance torna viável e mais provável que as diversas áreas dentro de uma empresa atuem em conformidade com a legislação e com as políticas internas da própria empresa, criando-se um conjunto de rotinas e procedimentos para que, de maneira sistêmica e integrada, a empresa como um todo possa buscar estar em conformidade. ${ }^{30}$

Desde sua origem, o compliance subordinou-se aos departamentos jurídicos das empresas; atualmente, agregou também todos os processos realizados dentro da empresa, sendo necessário seu mapeamento e gestão para a construção de um programa. Por uma questão de governança corporativa e conflito de interesses, há uma forte tendência das empresas no Brasil em manter o compliance de forma autônoma e independente; no entanto, este tema ainda está muito polêmico, não há uma interpretação dominante e ele não faz parte do escopo deste estudo.

\subsection{AS TEORIAS RACIONALISTA E NORMATIVA}

O estudo aprofundado do compliance apoia-se em duas teorias amplas: a teoria racionalista e a teoria normativa ${ }^{31}$, que atribuem visões diferentes no comportamento e nas motivações não explícitas dos agentes relativamente ao cumprimento de compliance.

\footnotetext{
${ }^{29}$ FOORTHUIS, 2014.

30 FERRAZ JÚNIOR, Tércio Sampaio. Todos ganham com o compliance. Disponível em: <http://www.cade.gov.br/noticias/cade-apresenta-proposta-de-guia-sobre-programas-de-complianceconcorrencial/guia-compliance-versao-preliminar.pdf $>$. Acesso em: 3 jan 2020.

${ }^{31}$ LI, H., SARATHY, R., Zhang, J. Understanding Compliance with Use Policy: An Integrative Model Based on Command-and-Control and Self-Regulatory Approaches. Proceedings of ICIS 2010, St. Louis, USA. Disponível em: <https://pdfs.semanticscholar.org/8ed7/1169069e13254c101493b24f63d758982a1d.pdf>. Acesso em: 3 jan.2020. e BULGURCU, B., CAVUSOGLU, H., BENBSAT, I. Information Security Policy Compliance: Na Empirical Study of Rationality-Based Beliefs and Information Security Awareness. MIS, 2010,Quarterly, $\quad$ v. $\quad 34, \quad \mathrm{n}^{\circ}$. $3, \quad$ p. $\quad 523-548 . \quad$ Disponível em: <http://130.18.86.27/faculty/warkentin/BIS9613papers/MISQ_SpecialIssue/BulgurcuCavusogluBenbasat2010_ MISQ34_RationalityAwareness.pdf>. Acesso em: 3 jan. 2020.
} 
A teoria racionalista atém-se aos cálculos de benefícios e custos efetuados pelo agente na sua decisão em adequar-se ou não às regras de compliance. Percebe-se os agentes fazendo uma escolha racional de alternativas. Nesta ótica, os incentivos e desincentivos alterarão o resultado dos cálculos do agente; portanto, uma abordagem importante usada para este resultado é a imposição ou comando e controle, considerando-se que o comportamento repudiado é desencorajado por meio da punição. Por outro lado, as recompensas são um meio adicional na perspectiva realística ao estimular o cumprimento das regras de compliance ao trocar o cálculo do custo-benefício como vantajoso para o agente.

A teoria normativa atém-se à cooperação e assistência como um meio para estimular o cumprimento das regras de compliance. A abordagem desta teoria refere-se às ações baseadas em identidades, papéis, obrigações e ações apropriadas, justas e legítimas.

Esta teoria não toma a posição de que o comportamento de um agente é irracional, mas tende a ampliar o âmbito para evitar a direção da discussão para custos e benefícios. Presumese que os agentes submeter-se-ão às regras e práticas que ligam identidades específicas com situações específicas. Essas regras devem ser internalizadas e encaradas como legítimas àqueles que se lhe submetem. A atuação do compliance pode ser dificultada se as regras são ambíguas, complexas ou alteram-se continuamente, se forem muito numerosas ou não facilmente disponíveis. Por conseguinte, o não atendimento ao compliance deveria ser administrado em vez de ser sancionado. ${ }^{32}$

Na percepção desta teoria, os métodos para aumentar a adesão ao compliance devem ater-se em aumentar a capacidade do agente em aderir ao compliance, cuja melhor aproximação é a cooperação, o suporte e o encorajamento ao discurso compartilhado para tornar as regras mais claras, mais persuasivas e mais fáceis de comprometimento. ${ }^{33}$

Cabe esclarecer que as duas teorias acima analisadas não se excluem mutuamente, mas complementam-se e fornecem perspectivas diferentes na análise de influências no comportamento do agente em relação à adesão às regras de compliance. ${ }^{34}$

Apesar de as duas teorias parecerem complementares, a teoria racionalista parece muito menos partidária do espírito do compliance e da ética empresarial em si, cujo principal valor é a integridade que a permeia. Do ponto de vista empresarial, a teoria racionalista parece menos educativa e também menos atrativa em uma perspectiva de longo prazo, pois ela não

\footnotetext{
${ }^{32}$ MALLOY, T.F.: Regulation, Compliance and the Firm. Temple Law Review, V. 76 (2003). Disponível em: <google.books.com.br>. Acesso em: 3 jan. 2020.

${ }^{33}$ RODERICK, 1996; FOORTHUIS, 2014.

${ }^{34}$ FOORTHUIS, 2014.
} 
adere aos objetivos da empresa na construção contínua de uma cultura de ética e integridade ao valorizar uma atitude racional e egocêntrica do agente.

\subsection{O PROGRAMA DE COMPLIANCE}

Conforme já investigado previamente, o compliance é uma ferramenta à disposição das empresas para o cumprimento de normas internas, diretrizes, políticas e legislação. De que forma operacionaliza-se o compliance? A resposta, cujo detalhamento é o tema deste tópico, é o programa de compliance, que é baseado em uma metodologia para alcançar-se o cumprimento de tais regras e normativos. O cumprimento dessas regras dão à empresa segurança, proteção e transparência.

O programa de compliance é a ferramenta utilizada para alcançar-se os objetivos do compliance que são: proporcionar confiança aos acionistas/sócios e aos administradores da empresa quanto ao atendimento às leis e regulamentações locais, bem como o atendimento às políticas, às normas e aos procedimentos internos, de forma a manter a alta qualidade do controle interno, assegurar o cumprimento da missão e visão da empresa e mitigar os riscos associados aos negócios e processos; proteger os ativos, a imagem e a reputação da empresa e de suas unidades de negócio.

Apesar de ter surgido para dar conformidade aos processos das empresas, o programa de compliance ganhou força por ser uma ferramenta importante na gestão da ética empresarial, promovendo uma atuação ilibada; nota-se que é composto por procedimentos preventivos da organização que desenvolvem mecanismos e normas para cumprir-se todos os requisitos internos de sua atuação, aplicando a fiscalização, a auditoria, o cumprimento do código de conduta e o incentivo à denúncias de irregularidades por meio da promoção de campanhas de comunicação interna e de canais desenvolvidos para essa finalidade. O programa é uma política interna responsável por garantir o cumprimento de todas as regulamentações externas, regulando, identificando e tratando qualquer desvio ou inconformidade que possa ocorrer.

A implementação eficiente de um programa de compliance resulta no fortalecimento da cultura organizacional e no pleno cumprimento dos seus processos. Além desses fatores, referido programa otimiza os negócios e protege a reputação da empresa; por fim, ainda promove a imagem da organização, que pode obter o reconhecimento público pelo Ministério 
da Transparência, Fiscalização e Controladoria Geral da União (antiga CGU) como empresa pró-ética, fortalecendo ainda mais a sua reputação.

Neste contexto, o programa de compliance é composto por elementos essências que serão esclarecidos adiante. ${ }^{35}$

O comprometimento da empresa e de seus administradores é o valor fundamental para o sucesso do programa. O comprometimento concretiza-se por meio dos seguintes atributos: envolvimento da alta direção, recursos adequados e autonomia e independência do gestor do programa. Por envolvimento da alta direção entende-se a inserção do compliance como um valor fundamental na cultura corporativa, a ser garantido mediante sua inclusão na agenda fixa dos órgãos da administração ou da pessoa responsável em determinar a orientação geral dos negócios da empresa e aprovar suas demonstraçōes financeiras.

O programa de compliance bem estruturado é normalmente precedido da realização de uma análise aprofundada dos riscos a que a empresa está exposta em suas atividades. Entre outros fatores, tais riscos costumam variar de acordo com o tamanho do negócio da empresa, os setores de atuação, sua posição nesses mercados, a capilaridade de suas atividades, a quantidade de colaboradores empregados e o seu grau de instrução. A empresa deve realizar uma análise individualizada dos riscos atrelados às suas atividades, classificando os níveis de risco a que está exposta em diversas áreas e priorizando as atividades de compliance sobre aquelas que apresentam maior risco associado.

Os treinamentos oferecidos aos colaboradores da empresa, seus fornecedores e prestadores de serviços são uma forma bastante adequada para transmitir-se cada um dos objetivos e regras do programa. É também por meio deles que os agentes sensibilizam-se e compreendem corretamente a importância do compliance e têm a oportunidade de esclarecer dúvidas específicas sobre os procedimentos, o que geralmente contribui para seu engajamento nas atividades. O canal de denúncias também é uma importante ferramenta que permite o recebimento de denúncias, aumentando, assim, as possibilidades de ter-se ciência sobre as irregularidades.

O monitoramento efetivo do programa de compliance é um fator importante para o seu sucesso. Monitora-se a análise do funcionamento adequado dos processos e controles desenvolvidos e a verificação da efetividade prática desses processos e controles.

Neste capítulo discorreu-se brevemente sobre o conteúdo e a importância do programa de compliance. No próximo capítulo serão analisadas a relações entre o programa de

${ }^{35}$ CADE. Disponível em: <http://www.cade.gov.br/noticias/cade-apresenta-proposta-de-guia-sobre-programasde-compliance-concorrencial/guia-compliance-versao-preliminar.pdf $>$. Acesso em: 2 jan. 2020. 
compliance, da maneira como é conhecido internacionalmente, e o programa de integridade, regulamentado no bojo da legislação anticorrupção brasileira.

Após a breve pesquisa sobre ética empresarial e compliance, o estudo propõe-se a analisar o tema de integridade; não só na definição de conceitos e hierarquias, como também da boa escolha do legislador brasileiro em utilizar esta expressão como um programa de integridade. O termo Integridade aspira a virtudes e nele residem valores, mas a integridade também é obedecedora de todas as categorias de regras, escritas e não escritas. O estudo completo da integridade termina relacionando cidadãos, sociedade, organização e Estado.

A definição de integridade do Tribunal de Contas da União faz referência à integridade e ética empresarial. Utilizando-se a definição de integridade proferida pelo Tribunal de Contas da União, pode-se adaptá-la também para definir integridade relativamente à empresa privada e seus colaboradores. A integridade refere-se aos valores e princípios pessoais que regem o comportamento de cada colaborador da empresa. A integridade decorre da virtude e da incorruptibilidade, portanto, da ausência de fraude e corrupção. Um colaborador íntegro não se corrompe por situações momentâneas, infringindo as normas e as leis, os valores e os princípios éticos. Por outro lado, um colaborador não íntegro poderá seguir as normas, as leis e os valores éticos somente para evitar problemas e não em razão de seu caráter. Em virtude disso, é relevante que as organizações visem não somente a promoção da cultura ética, mas também a integridade de seus colaboradores, que redundará na integridade organizacional como um todo. ${ }^{36}$

Uma leitura dos guias emitidos pelas autoridades constata que elas não revelam qualquer preocupação em explorar a dimensão axiológica ${ }^{37}$ da integridade como norma-

\footnotetext{
${ }^{36}$ TRIBUNAL DE CONTAS DA UNIÃO. Referencial de combate à fraude e corrupção: aplicável a órgãos e entidades da Administração Pública, 2017. Disponível em: <https://portal.tcu.gov.br/bibliotecadigital/referencial-de-combate-a-fraude-e-corrupcao.htm>. Acesso em: 3 jan. 2020.

${ }^{37}$ Definição de Axiologia: "também chamada de teoria de valor, é o estudo filosófico prático que busca entender a natureza dos valores e os juízos de valor e como eles surgem na sociedade. A axiologia está intimamente relacionada a dois outros domínios da filosofia: ética e estética. Todos os três ramos lidam com o valor. Enquanto a ética preocupa-se com a bondade, tentando entender o que é bom e o que significa ser bom, a estética está preocupada com a beleza e a harmonia. Com isso, busca entender a beleza e o que ela significa ou como ela é definida. A axiologia é um componente necessário da ética e da estética. Porque é preciso usar conceitos de valor para definir "bondade" ou "beleza" e, portanto, é preciso entender o que é valioso e porquê. A compreensão desses valores também nos ajuda a determinar o motivo de uma ação. Disponível em: <https://www.significados.com.br/?s=axiologia>. Acesso em: 3 jan. 2020.
} 
princípio. A esse respeito, algo expressivo encontra-se no Referencial de combate à fraude e corrupção do Tribunal de Contas da União. O documento reproduz a visão do Tribunal de Contas sobre a cultura ética e integridade:

\begin{abstract}
Ética organizacional decorre dos valores e princípios da organização. Os valores organizacionais são, atualmente, expressos por intermédio de suas principais crenças, que ficam subjacentes à suas escolhas, como a defesa do interesse público, a imparcialidade, a transparência e o accountability, devendo ser normatizados por intermédio de código de ética. Os princípios decorrem, por sua vez, da transformação dos valores éticos em normas ou códigos de conduta, com o propósito de, por exemplo, evitar conflito de interesse, recebimento de presentes, clientismo, nepotismo e outras formas de favoritismo. Integridade significa mais do que simplesmente observar as normas, os códigos e as leis decorrentes dos valores e princípios. AS normas e leis proporcionam um limite mínimo, um ponto de partida para a moralidade. É preciso mais do que isso. ${ }^{38}$
\end{abstract}

Por fim, o Tribunal de Contas da União esclarece de que forma a concretização dos princípios da boa fé objetiva e do abuso do direito, entre outros, relacionam-se ao sistema de prevenção à corrupção, com base na integridade, ao referir-se às boas práticas internacionais:

[...] Tais práticas são recepcionadas pela tradição legal brasileira, à luz da qual deve se dar a sua leitura. Um sistema de integridade enquanto convenção privada ou pública tem reflexos nas relações entre cidadãos, entre agentes econômicos e entre todos esses e o Estado e a sociedade. Daí o sistema de prevenção à corrupção, fundado na integridade, abre espaço à concretização dos princípios da boa fé objetiva, do abuso do direito, da função social do contrato, dos princípios que regem a administração pública e a república, além dos princípios da governança. Esse estoque principiológico indica o tamanho do desafio da gestão da ética no Brasil.

Além da integridade como principal valor da ética, passa-se a analisar o programa de integridade para prevenção, detecção e remediação dos atos lesivos previstos na Lei $\mathrm{n}^{\circ}$. 12.846/2013 ${ }^{39}$, cujo conteúdo, além da tipificação de suborno de funcionário púbico, também adiciona a tipificação de fraudes nos processos de licitação e execução de contratos com o setor público.

O Decreto $n^{\circ} .8 .420 / 2015^{40}$ definiu no seu art. 41 o que é Programa de Integridade:

\footnotetext{
${ }^{38}$ TRIBUNAL DE CONTAS, 2017.

${ }^{39}$ BRASIL.Lei no $\mathbf{0}$ 12.846, de 1 de agosto de 2013. Dispõe sobre a responsabilização administrativa e civil de pessoas jurídicas pela prática de atos contra a administração pública, nacional ou estrangeira, e dá outras providências. Disponível em: <http://www.planalto.gov.br/ccivil_03/_ato2011-2014/2013/lei/112846.htm>. Acesso em: 2 jan. 2020.

${ }^{40}$ BRASIL. Decreto $n^{\circ} .8 .420$, de 18 de março de 2015. Regulamenta a Lei $n^{\circ} 12.846$, de $1^{\circ}$ de agosto de 2013 , que dispõe sobre a responsabilização administrativa de pessoas jurídicas pela prática de atos contra a
} 
Programa de integridade consiste, no âmbito de uma pessoa jurídica, no conjunto de mecanismos e procedimentos internos de integridade, auditoria e incentivo à denúncia de irregularidades e na aplicação efetiva de códigos de ética e de conduta, políticas e diretrizes com objetivo de detectar e sanar desvios, fraudes, irregularidades e atos ilícitos praticados contra a administração pública, nacional ou estrangeira.

Diante do conceito acima, verifica-se que o programa de integridade tem como foco medidas anticorrupção adotadas pela empresa, especialmente aquelas que visem à prevenção, detecção e remediação dos atos lesivos contra a administração pública nacional e estrangeira previstos na Lei $\mathrm{n}^{\circ}$. 12.846/2013. O programa de integridade é um programa de compliance específico. Empresas que já possuem programa de compliance, ou seja, uma estrutura para o bom cumprimento de leis em geral, devem trabalhar para que medidas anticorrupção sejam integradas ao programa já existente. Mesmo empresas que possuem e aplicam medidas dessa natureza, sobretudo para atender a legislações antissuborno estrangeiras, devem atentar-se para a necessidade de adaptá-las à nova lei brasileira, em especial para refletir a preocupação com a ocorrência de fraudes em licitações e na execução de contratos com o setor público. ${ }^{41}$

O programa de integridade implica necessariamente em um grau de efetividade mais profundo do que o programa de compliance. Antônio Fonseca analisa o fato de a legislação brasileira basear-se na integridade:

[...] a lei brasileira não está baseada no compliance, mas sim,na integridade. Esse conceito é mais abrangente que o primeiro, pois estabelece a necessidade de fazer certo por convicção e não por imposição da lei. Ser íntegro pressupõe-se alinhamento com caráter, honestidade, ética, moral. Portanto, um mecanismo de integridade vai além de simplesmente cumprir leis e códigos,sendo, dessa forma, mais amplo do que o compliance. ${ }^{42}$

A partir da intelecção dos conceitos acima expostos de ética empresarial, compliance e integridade, passa-se a estudar a dinâmica entre eles, cujos conceitos sobrepõem-se em vários

administração pública, nacional ou estrangeira e dá outras providências. Disponível em: <http://www.planalto.gov.br/ccivil_03/_Ato2015-2018/2015/Decreto/D8420.htm>. Acesso em: 3 jan. 2020.

${ }^{41}$ CGU. Programa de Integridade. Diretrizes para Empresas Privadas. Disponível em: $<$ https://www.cgu.gov.br/Publicacoes/etica-e-integridade/arquivos/programa-de-integridade-diretrizes-paraempresas-privadas.pdf>. Acesso em: 2 jan. 2020.

${ }^{42}$ GIOVANNI, Wagner. Lei Anticorrupção ajuda o Brasil. Jornal “o Estado de São Paulo”, 2017. 
aspectos e são objeto de interpretações diversas mesmo no entendimento de profissionais da área de compliance.

\section{A RELAÇÃO ENTRE A ÉTICA EMPRESARIAL E OS PROGRAMAS DE COMPLIANCE E INTEGRIDADE}

A relação direta de interdependência entre o compliance e a ética empresarial é muito forte, acrescentando-se que a integridade é o principal valor de um comportamento ético. $\mathrm{O}$ compliance traz uma ferramenta para consecução do maior desafio relativo a implantação de uma cultura ética nas organizações, qual seja, a metodologia, as técnicas e os mecanismos de integrar a ética na sua estratégia, decisões e ações. Para uma organização ser ética não basta a instituição de um código de ética ou conduta; ela precisa de sistemas, políticas e processos que integram os padrões de ética e integridade na vida da organização, além da instituição de um código de ética ou conduta, que conferem à empresa o status de uma organização ética. No entanto, para que o programa de compliance consiga produzir os resultados esperados, terá de ancorar-se em um ambiente organizacional que seja fortemente baseado em valores éticos. O contexto ético é a base para o programa de compliance, considerando-se que a ética e a integridade dão sustentação e sentido ao programa. O sistema de compliance somente dará resultado e houver uma forte cultura ética adotada pela direção da empresa.

Cada um dos sistemas de ética - compliance e integridade - precisa de regras e valores. Integridade é um convite à perfeição, o que não existe no contexto de compliance; mas também sabe-se que integridade perfeita é utopia.

O Guidelines Manual - Compliance and Ethics Program ${ }^{43}$ é o repositório estadunidense das boas práticas para um efetivo programa de ética e compliance. Neste manual, de forma equivocada, a palavra compliance aparece antes do termo Ethics, formando a expressão Compliance and Ethics Program. Ética é um conceito mais amplo e um princípio que guia o compliance.

Michaell Volkov $^{44}$ tece uma comparação entre ética e compliance cujo conteúdo expressa o desejo do setor empresarial: "quero uma empresa que reforce o termo ética e ético

\footnotetext{
43 UNITED STATES SENTENCING COMMIMSSION. Guidelines Manual - Compliance and Ethics Program. Disponível lem: <https://guidelines.ussc.gov/home>. Acesso em: 4 jan. 2020.

${ }^{44}$ Volkov, Michael. Ethics and Compliance, not Compliance and Ethics, 2015. Disponível em: < https://blog.volkovlaw.com/2015/03/ethics-and-compliance-not-compliance-and-ethics/>. Acesso em: 4 jan. 2020.
} 
em todas as oportunidades e quero ter certeza de que nós, como organização, somos mais do que cumpridores, somos éticos. ${ }^{45} \mathrm{O}$ autor comenta ainda sobre o degrau diferencial entre ética e compliance:

O perigo de enfatizar o compliance sobre a ética é baixar a barra de resultado (do sistema), o que significa que para ser ético tudo que temos a fazer é cumprir com a lei. Isso é um perigo real de perda de oportunidade. Se uma empresa pugna por uma cultura ética, então a empresa está definindo um objetivo otimístico, colocando desafios para ela mesmo, seus dirigentes e empregados, e fazendo a todos a pergunta: estão fazendo a coisa certa ou simplesmente o mínimo legal? ${ }^{46}$

Na essência, ética e compliance são lados diferentes da mesma moeda. O compliance atém-se ao cumprimento da lei, enquanto a ética requer que seja feito o que é correto, independentemente do que reza a lei. O compliance é algo que o governo demanda que seja realizado; a ética, por outro lado, é algo que se escolhe a considerar quando se implementa uma ação.

Indiferentemente de como as empresas rotulem a posição, a maioria dos órgãos de gestão corporativos sabem que a ética e o compliance tem uma forte influência na cultura empresarial. A cultura ética pode levar à falha ou ao sucesso corporativo. Talvez o mais desafiante neste tema seja como trazer um programa robusto de ética e compliance no ambiente de trabalho visando impedir o mau comportamento.

Com o objetivo de enfatizar as dificuldades de interpretação e diferenciação dos conceitos de integridade e compliance, apresenta-se o entendimento de Marcy Maslov sobre a força das palavras:

Palavras tem poder. Elas têm contexto, inspiram emoção e reação intangível, subconsciente e instintiva que nem sabemos como distinguir, mas que afeta o modo como pensamos, interpretamos, falamos e agimos. As ações, escolhas e decisões das pessoas podem ser justificadas com base no poder das palavras escritas e suas interpretadas nuances, seja positivas ou negativas. As palavras realmente têm poder para a pessoa média.

\footnotetext{
45 Texto original em inglês: "I want a company to reinforce the term ethics and ethical at every opportunity and I want to make sure that we, as an organization, are more than compliant, we are ethical."

46 Texto original em inglês: "The danger of emphasizing compliance over ethics is setting a low bar for achievement, meaning that to be ethical all we have to do is comply with the law. That is a real danger because it is a missed opportunity. If a company strives for a culture of ethics, then the company is setting an optimistic goal, challenging the company and its managers and employees, and requiring everyone to ask whether if they are doing the 'right' thing, not just the bare minimum legal thing?"
} 
A autora pronuncia-se também sobre o peso das palavras compliance e integridade e como elas são encaradas pela pessoa média:

Quando se fala compliance, o que instintivamente vem à tona? É uma reação positiva ou negativa? Para a maioria das pessoas, compliance significa compulsório e, portanto, alguma coisa desagradável ou indesejável. O compliance significa ausência ou de alguma forma limitação de liberdade, ou que existe alguma regra que temos de seguir. Isso pode ser bom ou ruim. Mas muita gente toma isso como ruim. [...] Quando eu falo a palavra integridade, o que instintivamente surge? [...] Para a maioria das pessoas esta palavra gera uma reação positiva.[...] As sindicâncias de compliance, de ética e auditorias deixam as pessoas desconfortáveis, mesmo que não tenham feito nada de errado. Promotores da integridade buscam comportamentos positivos. ${ }^{47}$

\section{CONSIDERAÇÕES FINAIS}

O programa de compliance é uma ferramenta corporativa cuja metodologia para sua efetivação está alicerçada na ética empresarial e na integridade como seu maior valor. A referência ao compliance traduz-se no seguimento dos textos normativos e regras, independentemente de o agente imbuir-se ou não dos valores expressados nas leis, regulamentos ou políticas para a qual mostrou cumprimento e adequação. Diversamente deste conceito, o comportamento ético empresarial requer que seja feito o que é correto, dentro dos padrões de moral e integridade, pessoal e corporativo. O agir ético é uma percepção de que se está acima de ser apenas cumpridor da lei, trata-se de integridade e valores pessoais em questão. Há uma grande diversidade de interpretação de conceitos nesta matéria pelos profissionais da área, levando-se em consideração que este tema está passando pelas portas da academia há pouco tempo.

\section{REFERÊNCIAS}

ABEND, Gabriel. Historicizing Business Ethics: The Origins of Business Ethics in American Universities, 1902-1936." Department of Sociology, New York University, 2011. Disponível em: <https://www.researchgate.net/publication/268279608_The_Origins of_Busines s_Ethics_in_American_Universities_1902-1936>. Acesso em: 30 dez. 2019.

\footnotetext{
${ }^{47}$ MASLOV, Marcy J. CORPORATE COMPLIANCE INSIGHTS. “Compliance Officer” VS. "Integrity Officer": you see, words have Power, 2017. Disponível em:

<https://www.corporatecomplianceinsights.com/compliance-officer-vs-integrity-officer/ >. Acesso em: 4 jan. 2020.
} 
BEGA, Patricia Fernandes; SÉLLOS-KNOERR, Viviane Coêlho de. O agir ético na sociedade de consumo como desafio à atividade empresarial. Revista Juridica, [S.1.], v. 3, n. 32, p. 454-470, dez. 2013. ISSN 2316-753X. Disponível em: <http://revista.unicuritiba.edu.br/index.php/RevJur/article/view/696/522>. Acesso em: 19 abr. 2020. doi:http://dx.doi.org/10.21902/revistajur.2316-753X.v3i32.696.

BRASIL. Decreto $\mathbf{n}^{\mathbf{0}} \mathbf{. 8 . 4 2 0}$, de 18 de março de 2015. Regulamenta a Lei $\mathrm{n}^{\circ} 12.846$, de $1^{\circ}$ de agosto de 2013, que dispõe sobre a responsabilização administrativa de pessoas jurídicas pela prática de atos contra a administração pública, nacional ou estrangeira e dá outras providências. Disponível em: <http://www.planalto.gov.br/ccivil_03/_Ato20152018/2015/Decreto/D8420.htm>. Acesso em: 3 jan. 2020.

Lei $\mathbf{n}^{\mathbf{0}}$. 12.846, de 1 de agosto de 2013. Dispõe sobre a responsabilização administrativa e civil de pessoas jurídicas pela prática de atos contra a administração pública, nacional ou estrangeira, e dá outras providências. Disponível em: <http://www.planalto.gov.br/ccivil_03/_ato2011-2014/2013/lei/112846.htm>. Acesso em: 2 jan. 2020.

CARDOSO, C.C. Éticas e política éticas em contexto empresarial. (Org.) RODRIGUES, S. B.; CUNHA, M. P. Estudos organizacionais: novas perspectivas na administração de empresas: uma coletânea luso-brasileira. Iglu: SP, 2000.

CGU. Programa de Integridade. Diretrizes para Empresas Privadas. Disponível em: $<$ https://www.cgu.gov.br/Publicacoes/etica-e-integridade/arquivos/programa-de-integridadediretrizes-para-empresas-privadas.pdf >. Acesso em 4 jan. 2020.

CADE. Disponível em: <http://www.cade.gov.br/noticias/cade-apresenta-proposta-de-guiasobre-programas-de-compliance-concorrencial/guia-compliance-versao-preliminar.pdf $>$.

Acesso em: 2 jan. 2020.

CENP. Disponível em: www.cenp.com.br/Site/cenp_revista/EDICAO_39.pdf. Acesso em: 2 jan 2020.

FERRAZ JÚNIOR, Tércio Sampaio. Todos ganham com o compliance. Disponível em: <http://www.cade.gov.br/noticias/cade-apresenta-proposta-de-guia-sobre-programas-decompliance-concorrencial/guia-compliance-versao-preliminar.pdf >. Acesso em: 3 jan 2020.

FOORTHUIS, Ralph; BOS, Erik. A Framework for Organizational Compliance Management Tactics. 2014.2 Disponível em: <https://www.researchgate.net/publication/220920993_A_Framework_for_Organizational_C ompliance_Management_Tactics>. Acesso em: 3 jan. 2020.

GIOVANNI, Wagner. Lei Anticorrupção ajuda o Brasil. Jornal “o Estado de São Paulo”, 2017.

INSTITUTO BRASILEIRO DE GOVERNANÇA CORPORATIVA. Disponível em: $<$ https://ibgc.org.br/>. Acesso em 2 jan. 2020. 
INSTITUTO BRASILEIRO DE DIREITO E ÉTICA EMPRESARIAL. Disponível em:< http://www.ibdee.org.br/>. Acesso em: 2 jan. 2020.

KOLB, Robert W. Encyclopedia of business ethics and society. ISBN 978-1-4129-1652-3. Thousand Oaks, Califórnia: SAGE Publications, Inc., 2008.

LAMBOY, Christian K. de; Risegato, Giulia G.A. Pappalardo; COIMBRA, Marcelo de Aguiar.Introdução ao Corporate Compliance, Ética e Integridade. Manual de Compliance. São Paulo: Instituto ARC, 2017.

LI, H., SARATHY, R., Zhang, J. Understanding Compliance with Use Policy: An Integrative Model Based on Command-and-Control and Self-Regulatory Approaches. Proceedings of ICIS 2010, St. Louis, USA. Disponível em: <https://pdfs.semanticscholar.org/8ed7/1169069e13254c101493b24f63d758982a1d.pdf>. Acesso em: 3 jan.2020. e BULGURCU, B., CAVUSOGLU, H., BENBSAT, I.

Information Security Policy Compliance: An Empirical Study of Rationality-Based Beliefs and Information Security Awareness. MIS, 2010, Quarterly, v. 34, $\mathrm{n}^{\circ}$. 3, p. 523-548. Disponível em: <http://130.18.86.27/faculty/warkentin/BIS9613papers/MISQ_SpecialIssue/BulgurcuCavusog luBenbasat2010_MISQ34_RationalityAwareness.pdf>. Acesso em: 3 jan. 2020.

MALlOY, T.F.: Regulation, Compliance and the Firm. Temple Law Review, V. 76 (2003). Disponível em: <google.books.com.br>. Acesso em: 3 jan. 2020.

NORMAN, Wayne. Business Ethics. Harvard Business School. Disponível em: $<$ https://www.hbs.edu/faculty/conferences/2016-newe/Documents/Norman,\%20Business \%20Ethics,\%20IntEncycEthics.pdf>. Acesso em: 30 dez. 2019.

RODERICK, P. (eds.). Improving Compliance with International Environmental Law. London: $\quad$ Earthscan, $1996 . \quad$ Disponível em: $<$ https://rmitchel.uoregon.edu/sites/rmitchel1.uoregon.edu/files/resume/chapters/1996ComplianceTheory.pdf $>$. Acesso em: 3 jan. 2020.

SCHWARTZ, Mark S. Business Ethics as an Academic Field in Encyclopedia of business ethics and society. ISBN 978-1-4129-1652-3. Thousand Oaks, Calfórnia: SAGE Publications, Inc., 2008, p. 217.

SROUR, Robert H. Ética Empresarial. Rio de Janeiro: Elsevier, 2013, p. 4.

UNITED STATES SENTENCING COMMISSION. Guidelines Manual - Compliance and Ethics Program. Disponível em: 〈https://guidelines.ussc.gov/home>. Acesso em: 4 jan. 2020.

VOLKOV, Michael. Ethics and Compliance, not Compliance and Ethics, 2015. Disponível em: < https://blog.volkovlaw.com/2015/03/ethics-and-compliance-notcompliance-and-ethics/>. Acesso em: 4 jan. 2020.

TRIBUNAL DE CONTAS DA UNIÃO. Referencial de combate à fraude e corrupção: aplicável a órgãos e entidades da Administração Pública, 2017. Disponível em: <https://portal.tcu.gov.br/biblioteca-digital/referencial-de-combate-a-fraude-ecorrupcao.htm>. Acesso em: 3 jan. 2020. 
VÁSQUEZ, Adolfo Sanches. Ética. 14.ed. Rio de Janeiro: Civilização Brasileira, 1993.

Unites States Sentencing Commission. Guidelines Manual - Compliance and Ethics Program. Disponível em: <https://guidelines.ussc.gov/home>. Acesso em: 2 jan. 2020.

ZAELKE, D., KANIARU, D., KRUZIKOVÁ, E. Making Law Work: Environmental Compliance \& Sustainable Development, Vol. I \& II. London: Cameron May Ltd. (2005); e também MITCHELL, R. B. Compliance Theory: An Overview. In: CAMERON, J., WERKSMAN, J., 